\title{
Chemical composition, antioxidant and antimicrobial activities of the essential oil of Vetiveria nigritana (Benth.) Stapf roots from Burkina Faso
}

\author{
Zenabou Semde $^{1 *}$, Jean Koudou ${ }^{2}$, Cheikna Zongo $^{3}$, Gilles Figueredo ${ }^{1}$, Marius K. Somda ${ }^{4}$, Leguet Ganou ${ }^{1}$, \\ Alfred S. Traore ${ }^{2}$ \\ ${ }^{1}$ Centre de Recherche en Sciences Biologiques Alimentaires et Nutritionnelles, Université Ouaga I J K Z, 03 BP7021 Ouagadougou 03, Burkina Faso. \\ ${ }^{2}$ Institut de Recherche en Sciences Appliquées et Technologies (IRSAT/CNRST), 03 BP7047 Ouagadougou 03, Burkina Faso. \\ ${ }^{3}$ Ecole Doctorale Pluridisciplinaire, Université Aube Nouvelle, 06 BP9283 Ouagadougou06, Burkina Faso. \\ ${ }^{4}$ Laboratoire d'Analyse des Extraits Végétaux (LEXVA Analytique), 63360 Saint-Beauzire, France.
}

\section{ARTICLE INFO}

Article history:

Received on: 05/05/2017

Accepted on: 21/06/2017

Available online: 14/08/2017

\section{Key words:}

Vetiveria nigritana, essential oil, antioxidant, antimicrobial.

\begin{abstract}
The main objective of this study was to determine the chemical composition, antioxidant and antimicrobial properties of the essential oil of Vetiveria nigritana (Benth.) Stapf roots growing in Burkina Faso. The composition of the essential oil was analyzed by GC and GC / MS. DPPH radical scavenging method and FRAP test were used to demonstrate the antioxidant activity of the essential oil. Antimicrobial activity of the essential oil was determined using disk diffusion method and broth microdilution method. The major components of the essential oil of $V$. nigritana were dehydronigritene, zizanoic acid, preziza-7-(15)-en-3-ol, khusian-2-ol, ziza-6(13)-en-3-beta-ol, prezizaan-15-al and khusimone. The essential oil demonstrated weak radical scavenging power with an IC50 of $28.35 \pm 0.58 \mu 1$ and a low reduction capacity. The essential oil showed a relative good inhibitory action against strains of Bacillus, Escherichia coli, Staphylococcus, Clostridium perfringens, Listeria monocytogenes, Micrococcus luteus, Enterococcus faecalis, Candida kefir and Saccharomyces cerevisiae with inhibition diameters ranging from $11.5 \pm 0.71 \mathrm{~mm}$ to $23.5 \pm 0.71 \mathrm{~mm}$. Minimum inhibitory concentrations of the essential oil of $V$. nigritana ranged from $1 \%$ to $8 \%$, minimum bactericidal concentrations from $2 \%$ to $4 \%$ with minimum fungicidal concentration of $4 \%$. These results suggest that essential oil of $V$. nigritana roots could be subjected for pharmaceutical drug formulations.
\end{abstract}

\section{INTRODUCTION}

Vetiveria nigritana (Benth.) Stapf (Poaceae) or black vetivergrass is a robust perennial grass growing from Mauritania to Nigeria and through to north-eastern, eastern and southern tropical Africa [1]. V. nigritana is a grass with short rhizomes which form compact tufts with numerous upright leaves. The leaves are very long ( 1 to 1.50 meters) and the flowers are

\footnotetext{
* Corresponding Author

Zenabou Semde, Centre de Recherche en Sciences Biologiques Alimentaires et Nutritionnelles, Université Ouaga I J K Z, 03 BP7021 Ouagadougou 03, Burkina Faso Institut de Recherche en Sciences Appliquées et Technologies (IRSAT/CNRST), 03 BP7047 Ouagadou, Burkina Faso. Email: nabousemde @ gmail.com
}

arranged in racemes composed of 15 to 20 whorls [2]. In some African countries such as Senegal and Mali, Vetiveria nigritana roots are used to flavor and disinfect drinking water. Flavored water is specially recommended in cases of infants and children common diarrhea [2]. V. nigritana roots are also used in the treatment of stomach aches in Nigeria [3]. The chemical composition of the essential oil of Vetiveria nigritana roots from different localities has already been elucidated by some studies revealing a variability of the constituents of this essential oil $[1,4-$ 6]. Few investigations have been found on the chemical composition and biological properties of $V$. nigritana from Burkina Faso. This study aimed to determine the proximate chemical composition, the antioxidant and antimicrobial activities of the essential oil extracted from $V$. nigritana roots from Burkina Faso. 


\section{MATERIAL AND METHODS}

\subsection{Plant material}

The roots of Vetiveria nigritana were collected in Loumbila near the city of Ouagadougou in July 2015. Voucher specimens are kept in the herbarium of the Biodiversity Information Center under the number ID 16964, University of Ouagadougou.

\subsection{Essential oil extraction}

The harvested roots of $V$. nigritana were air-dried and subjected to hydrodistillation during eight hours using a Clevenger-type apparatus [7]. The essential oil obtained was dried over anhydrous sodium sulfate and then stored at $4{ }^{\circ} \mathrm{C}$ waiting for analyzes. The extraction yield was calculated following this equation:

$\mathrm{R}(\%)=\mathrm{V} / \mathrm{W} \times 100$, where $\mathrm{V}$ is the Volume of essential oil in $\mathrm{ml}$ and $\mathrm{W}$ the weight of dried roots in $\mathrm{g}$.

\subsection{Chemical analyzes}

Chemical analyzes of the essential oil of $V$. nigritana roots was analyzed by gas chromatography (GC) and gas chromatography/mass spectrometry (GC/MS). GC analyzes were performed on a Hewlett-Packard HP 6890 equipped with a split/splitless injector $\left(280^{\circ} \mathrm{C}\right)$, a split ratio $1: 10$, using a HP-5 capillary column $(25 \mathrm{~m} \times 0.25 \mathrm{~mm}$, film thickness $0.25 \mathrm{~m})$. The oven temperature was programmed from 50 to $300^{\circ} \mathrm{C}$ at a rate of $5^{\circ} \mathrm{C} / \mathrm{min}$. Helium was used as carrier gas at a flow rate of $1.1 \mathrm{ml} / \mathrm{min}$. The injection sample consisted of $1.0 \mu \mathrm{l}$ of essential oil diluted to $10 \%(\mathrm{v} / \mathrm{v})$ with acetone. GC/MS analyzes were carried out on a Hewlett-Packard 5973/6890 system operating in EI mode (70eV) using two different columns: a fused silica HP-5 MS capillary column $(25 \mathrm{~m} \times 0.25 \mathrm{~mm}$, film thickness $0.25 \mathrm{~m})$, and a HP-Innowax capillary column $(60 \mathrm{~m} \times 0.25 \mathrm{~mm}$, film thickness $0.25 \mathrm{~m}$ ). The temperature program for HP-5MS column was $50^{\circ} \mathrm{C}$ (5 min) rising to $300^{\circ} \mathrm{C}$ at a rate of $5{ }^{\circ} \mathrm{C} / \mathrm{min}$ and for the $\mathrm{HP}$ Innowax column, $50-250^{\circ} \mathrm{C}$ at a rate of $5^{\circ} \mathrm{C} / \mathrm{min}$. Helium was used as carrier gas at a flow rate of $1.1 \mathrm{ml} / \mathrm{min}$. The oil components were identified by comparison of their mass spectra and their retention indices with those of reference compounds or with literature data [8-11]

\subsection{Antioxidant activity}

The antioxidant activity of the essential oil of $V$. nigritana roots was assessed by two methods: the DPPH radical scavenging method and the ferric reduction antioxidant power (FRAP) test.

\subsubsection{DPPH radical scavenging assay}

The radical scavenging power of the essential oil of $V$. nigritana roots was determined by the DPPH radical scavenging assay. This test was carried out as described previously by Joshi et al. (2010) [12]. Different amounts of the essential oil of $V$. nigritana $(5,10,15,20$ and $25 \mu \mathrm{l})$ were mixed with $5 \mathrm{ml}$ of an ethanolic solution of DPPH $(0.004 \%)$. The mixture thus obtained was incubated in the dark for $30 \mathrm{~min}$ and the absorbance then read at $517 \mathrm{~nm}$ using a spectrophotometer (JASCO V-530 UV/VIS Spectrophotometer). BHT, ascorbic acid and quercetin at a concentration of $0.005 \mathrm{M}(5,10,15,20$ and $25 \mu \mathrm{L})$ used as reference antioxidants and a negative control were also tested under the same conditions. A low absorbance indicates a high scavenging power; the inhibition percentage was calculated according to the following equation:

$\%$ inhibition $=\left[\left(\mathrm{A}_{\text {blank }}-\mathrm{A}_{\text {sample }}\right) / \mathrm{A}_{\text {blank }}\right] \times 100$ where $A_{\text {blank }}$ is the absorbance of the negative control and $A_{\text {sample }}$ the absorbance of the essential oil.

The antioxidant activity of the essential oil of $V$. nigritana was expressed as the inhibitory concentration 50 (IC50) which is defined as the amount of essential oil required to reduce the initial concentration of DPPH by 50\%. The IC50 was calculated graphically using a linear regression $[\%$ inhibition $=\mathrm{f}$ (concentrations)]. Assay was done in triplicate and the standard solutions as well as the DPPH solution were prepared and used the same day.

\subsubsection{Ferric reduction antioxidant power (FRAP)}

The reducing power of the essential oil of $V$. nigritana was determined following the method used by Joshi et al. (2010) [12]. Different amounts of essential oil $(5,10,15,20$ and $25 \mu \mathrm{l})$ were mixed with $2.5 \mathrm{ml}$ of phosphate buffer $(200 \mathrm{mM}, \mathrm{pH} 6.6)$ and $2.5 \mathrm{ml}$ of potassium ferricyanide $(1 \%)$. The mixture was incubated at $50^{\circ} \mathrm{C}$ for $30 \mathrm{~min}$ and then $2.5 \mathrm{ml}$ of trichloroacetic acid $(10 \%)$ were added to the mixture followed by centrifugation at $600 \mathrm{~g}$ for $10 \mathrm{~min}$. The supernatant was collected $(5 \mathrm{ml})$ and mixed with $5 \mathrm{ml}$ of distilled water and then $1 \mathrm{ml}$ of iron chloride $\left(0.1 \% \mathrm{FeCl}_{3}\right)$ was added to the mixture and the absorbance measured at $700 \mathrm{~nm}$ $\begin{array}{lllll}\text { using a spectrophotometer (JASCO } & \text { V-530 UV/VIS }\end{array}$ Spectrophotometer). Ascorbic acid (0.1M) and quercetin (0.1M) were used as standards; a negative control (blank) was also included in each test. The standards and the blank were subjected to the same procedure as the essential oil. An increase in absorbance indicates an increase of the reducing power.

\subsection{Antimicrobial activity 2.5.1 Microbial strains}

Twenty (20) bacterial strains and four (04) fungal strains were used for antimicrobial testing. Gram positive bacteria used were: Bacillus cereus LMG 13569, Bacillus subtilis ssp subtilis ATCC 6051, Clostridium perfringens, Enterococcus faecalis ATCC 19433, Listeria monocytogenes NCTC 9863, Micrococcus luteus SKN 624, Staphylococcus aureus ATCC 2523, Staphylococcus aureus ATCC 25923, Staphylococcus aureus toxin $(\mathrm{A}+\mathrm{B})$ and Staphylococcus hominis B246. Gram negative bacteria were represented by Escherichia coli 81nr.149 SKN 541, Escherichia coli ATCC 25922, Pseudomonas aeruginosa ATCC 9027, Salmonella enteridis P167807, Salmonella infantis SKN 557, Salmonella nigeria SKN 1160, Salmonella typhimurium SKN 
1152, Shigella dysenteria 370, Shigella flexneri USCC 2007 and Yersinia enterocolitica 8A30 SKN 601. Fungal strains tested were Candida albicans, Candida kefir, Candida tropicalis and Saccharomyces cerevisiae KVL 013. All microorganisms were kindly provided by Food Technology Department (CNRST/IRSAT/DTA) and Center for Research in Biological, Food and Nutritional Sciences (CRSBAN) of Burkina Faso.

\subsubsection{Agar disc diffusion method}

The antimicrobial activity of the essential oil of $V$. nigritana roots was carried out by the agar disc diffusion method. The tests were done on Mueller Hinton agar for the bacterial strains and on Sabouraud dextrose agar for the fungal strains following the method used by Bassolé et al. (2005) [7].

Microbial cultures of 18-24 hours were prepared in nutrient broth for the bacterial strains and in Sabouraud broth for the fungal strains and then diluted with sterile saline solution $(\mathrm{NaCl} 0.9 \%)$ to adjust the density of the inoculums to that of McFarland standard 0.5. The Petri dishes containing sterile and solid Mueller-Hinton agar or Sabouraud dextrose agar were inoculated with this microbial suspension. Sterile blank discs (6 mm diameter) were impregnated with $V$. nigritana essential oil (15 $\mu \mathrm{l}$ per disc) and then placed on the surface of the agar previously inoculated. The Petri dishes were then aerobically incubated at 37 ${ }^{\circ} \mathrm{C}$ for the bacterial strains and at $30^{\circ} \mathrm{C}$ for the fungal strains for 24 hours. The sensitivity of microbial strains to the essential oil of $V$. nigritana is determined by measuring the inhibition diameter (ID). For the evaluation of the inhibition diameters (ID), the criteria used by Carovic-Stanko et al. (2010) [13] were considered:

- $\quad$ ID $>15 \mathrm{~mm}$ : the essential oil has a high inhibitory action

- $10 \mathrm{~mm} \leq \mathrm{ID} \leq 15 \mathrm{~mm}$ : the essential oil has a moderate inhibitory action

- $\quad$ ID $<10 \mathrm{~mm}$ : the essential oil has a weak inhibitory action Tetracycline $(30 \mu \mathrm{g})$ and ciprofloxacin $(5 \mu \mathrm{g})$ were used as positive control for bacterial strains and nystatin (100 UI) for fungal strains. All tests were performed in duplicate.

\subsubsection{Determination of minimum inhibitory concentration (MIC), minimum bactericidal concentration (MBC) and minimum fungicidal concentration (MFC)}

The broth microdilution method [14] was used to determine the minimum inhibitory concentration (MIC), the minimum bactericidal concentration (MBC) and the minimum fungicidal concentration (MFC) of the essential oil of Vetiveria nigritana roots. All tests were carried out in Mueller-Hinton broth $(\mathrm{MH})$ for bacterial strains and in Sabouraud broth for fungal strains. The broth was supplemented with Tween 80 at a concentration of $0.5 \%(\mathrm{v} / \mathrm{v})$ in order to improve the solubility of the essential oil. A serial dilution of the essential oil of $V$. nigritana was prepared in a 96 well microplate containing $\mathrm{MH}$ broth or Sabouraud broth in a range of $0.03 \%$ to $8 \%(\mathrm{v} / \mathrm{v})$. Overnight broth cultures (18-24 hours) of each strain were prepared in nutrient broth for the bacterial strains and in
Sabouraud broth for the fungal strains. The density of the inoculums was adjusted with sterile saline solution $(0.9 \% \mathrm{NaCl})$ to the McFarland standard 0.5 corresponding to $10^{8} \mathrm{CFU} / \mathrm{ml}$. Then $10 \mu \mathrm{l}$ of these inoculums diluted were added in the well. For each microbial strain a positive growth control (no essential oil added in the well) and a negative growth control (no inoculum, no essential oil added in the well) were included in the test. The microplate thus seeded, was incubated aerobically at $30^{\circ} \mathrm{C}$ for the fungal strains and at $37^{\circ} \mathrm{C}$ for the bacterial strains and the MICs determined after 24 hours of incubation. The MIC is considered to be the lowest concentration of essential oil which does not show visible growth after $24 \mathrm{~h}$ of incubation. To determine the MBC, 10 $\mu \mathrm{l}$ of microbial suspension was taken from the wells of concentration greater than or equal to MIC and inoculated on the Mueller-Hinton agar or Sabouraud agar and then incubated for 24 hours at $37^{\circ} \mathrm{C}$ or $30^{\circ} \mathrm{C}$ depending on the strains. The lowest essential oil concentration at which no growth was observed on the agar after $24 \mathrm{~h}$ of incubation is considered as MBC. The ratio MBC / MIC was used to determine the intrinsic activity (bactericidal or bacteriostatic) of the essential oil of Vetiveria nigritana roots, considering that:

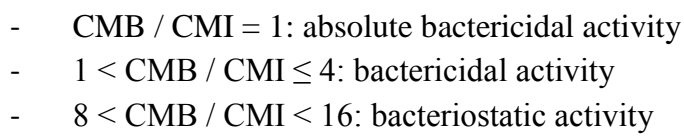

\section{RESULTS AND DISCUSSION}

\subsection{Chemical analysis}

The hydodistillation of Vetiveria nigritana roots enabled us to obtain a yellowish-colored essential oil with an extraction yield of $0.22 \pm 0.038 \%$. This yield is very low compared to those of $2 \%(\mathrm{~W} / \mathrm{W})$ and $1.35 \%(\mathrm{~V} / \mathrm{W})$ obtained respectively by Khalil and Ayoub (2011) and Champagnat et al. (2006) [4, 6]. This difference could be due to the difference of extraction methods, the extraction time, the harvesting time or the geographical location of the plant $[15,16]$.

The chemical composition of essential oil of V. nigritana roots is given in table 1. Twenty seven (27) compounds representing $75.237 \%$ of the essential oil of $V$. nigritana were identified. The relative abundance of some components of the essential oil is shown in figure 1. Dehydronigritene $(24.24 \%)$, zizanoic acid (11.48\%), preziza-7-(15)-en-3-ol (6.42\%), khusimol + Preziza-7(15)-en-12-ol (5.83\%), khusian-2-ol (5.09\%), ziza6(13)-en-3-beta-ol (3.21\%), prezizaan-15-al (3.00\%) and khusimone $(2.69 \%)$ are the major constituents of this essential oil. The chemical composition of the essential oil of $V$. nigritana from Burkina Faso differs from that of Mali, whose major compounds were prezizanoic acid (15\%), preziza-7-(15)-en-12-ol (9.5\%), cedren-8-en-15-ol (6.2\%), preziza-7-(15)-en-3 $\alpha$-ol (6\%) and zizanoic acid (5.9\%) [6]. Longifolene D (25.1\%), 2hydroxycyperol $(9.7 \%)$ and aromadendrene oxide $(8.8 \%)$ were identified by Khalil and Ayoub (2011) [4] as the major constituents of the essential oil of $V$. nigritana roots from Sudan. 
Table 1: Chemical composition of the essential oil of Vetiveria nigritana roots.

\begin{tabular}{llll}
\hline No. & $\begin{array}{c}\text { Retention } \\
\text { time }(\mathbf{m n})\end{array}$ & \multicolumn{1}{c}{ Component } & $\begin{array}{c}\text { Proportion } \\
(\boldsymbol{\%})\end{array}$ \\
\hline 01 & 12.13 & Nor Nigritene isomer & 2.152 \\
02 & 12.38 & Dehydronigritene & 24.246 \\
03 & 12.71 & Nigritene & 0.467 \\
04 & 12.87 & Acoradiene & 0.117 \\
05 & 12.97 & Beta-Funebrene & 0.567 \\
06 & 13.14 & Beta-Gurgunene & 0.202 \\
07 & 13.42 & Prezizaene & 0.206 \\
08 & 13.48 & Zizanene & 0.188 \\
09 & 13.69 & Cis-Eudesma-6-11-diene & 0.142 \\
10 & 13.75 & Delta-Selinene & 0.086 \\
11 & 13.93 & Delta-Amorphene & 0.252 \\
12 & 14.20 & Delta-Cadinene+Inconnu MW204 & 1.132 \\
13 & 14.35 & Zonarene & 0.169 \\
14 & 14.53 & Elemol & 0.378 \\
15 & 14.66 & Béta-Vetivenene & 0.582 \\
16 & 15.03 & 15-Nor-prezizaan-7-one & 1.166 \\
17 & 15.24 & Cis Dihydro-Mayurone & 0.977 \\
18 & 15.28 & Khusimone & 2.693 \\
19 & 15.49 & Epi-Cedrol & 1.601 \\
20 & 15.72 & Alpha-Copaen-ol & 1.87 \\
21 & 15.86 & Prezizaan-15-al & 3.007 \\
22 & 16.00 & Preziza-7(15)-en-3-ol & 6.425 \\
23 & 16.23 & Khusian-2-ol & 5.099 \\
24 & 16.31 & Ziza-6(13)-en-3-beta-ol+inconnu MW 220 & 3.217 \\
25 & 16.84 & Khusimol+Preziza-7(15)-en-12-ol & 5.838 \\
26 & 17.49 & Zizanoic acid & 11.488 \\
27 & 17.58 & Prezizanoic acid & 0.97 \\
& & Total & $\mathbf{7 5 . 2 3 7}$ \\
\hline & & &
\end{tabular}

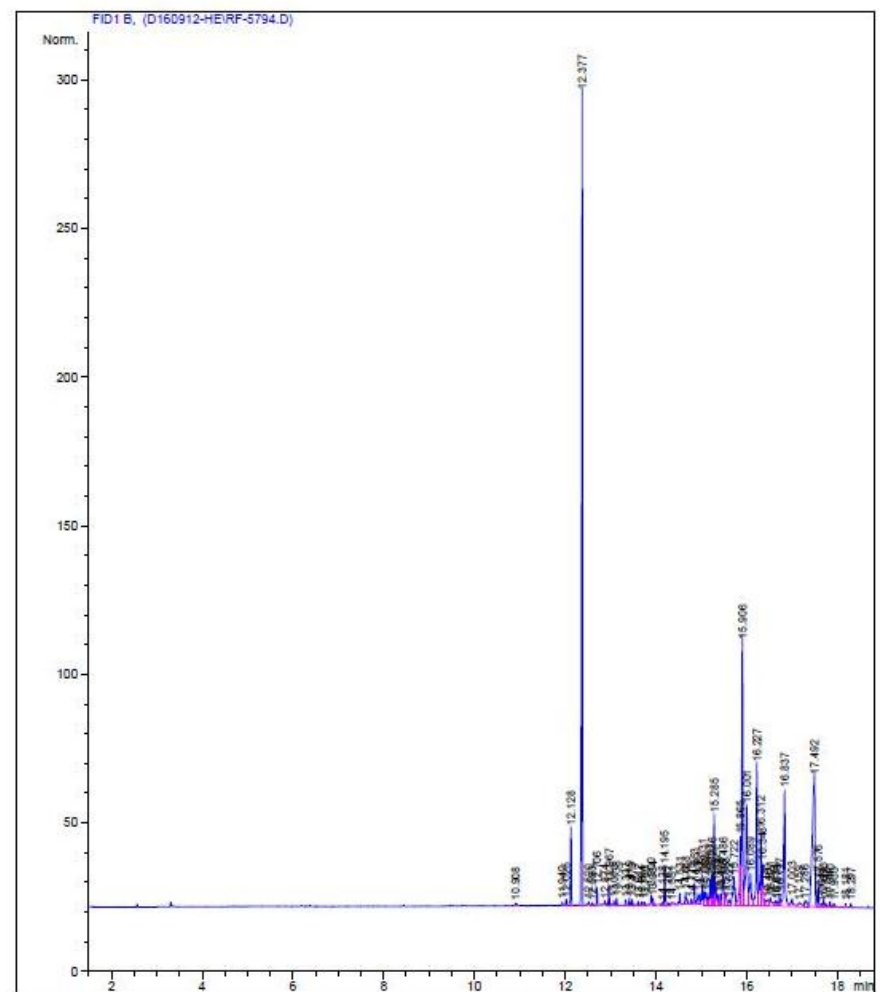

Fig. 1: Chromatogram of the essential oil of Vetiveria nigritana roots.

According to some authors, principal factors which determine the composition and yield of the essential oil obtained could include seasonal and maturity variation, geographical origin, genetic variation, growth stages, and postharvest drying and storage [17-19].

\subsection{Antioxidant activity}

The antioxidant capacity of the essential oil of $V$. nigritana was determined by comparison with the activities of known antioxidants, such as BHT, ascorbic acid, and quercetin.

DPPH is widely used to test the ability of compounds to act as free radical scavengers or hydrogen donors. The radical scavenging power of the essential oil of $V$. nigritana roots and reference antioxidants is showed in figure 2 . The results presented in figure 2 show that as the amount of essential oil increases, the DPPH radical inhibition percentage also increases. Thus, the DPPH radical inhibition power of the essential oil is concentration dependent. The inhibitory concentrations (IC50) of the essential oil of $V$. nigritana roots and standard antioxidants are shown in Table 2. The highest IC50 was obtained with $V$. nigritana $(28.35 \mu \mathrm{l})$ essential oil and the lowest one with quercetin $(12.45 \mu 1)$. Essential oil of Vetiveria nigritana possessed a radical scavenging power, but this activity is lower as compared to quercetin $(12.45 \mu \mathrm{l})$ and ascorbic acid $(18.33 \mu \mathrm{l})$ but quite similar to BHT $(26.94 \mu 1)$.

Table 2: Inhibitory concentration (IC50).

\begin{tabular}{llcc}
\hline $\begin{array}{l}\text { Essential oil and } \\
\text { standards }\end{array}$ & Regression equation & $\mathbf{R}^{\mathbf{2}}$ & IC50 $(\boldsymbol{\mu l})$ \\
\hline Quercetin $(0.005 \mathrm{M})$ & $\mathrm{y}=2.7792 \mathrm{x}+15.388$ & 0.99 & $12.45 \pm 0.25$ \\
Ascorbic acid $(0.005 \mathrm{M})$ & $\mathrm{y}=2.3558 \mathrm{x}+6.8831$ & 0.99 & $18.33 \pm 0.65$ \\
BHT $(0.005 \mathrm{M})$ & $\mathrm{y}=1.8254 \mathrm{x}+0.831$ & 0.99 & $26.94 \pm 0.32$ \\
Vetiveria nigritana & $\mathrm{y}=1.65 \mathrm{x}+3.2306$ & 0.99 & $28.35 \pm 0.58$ \\
\hline
\end{tabular}

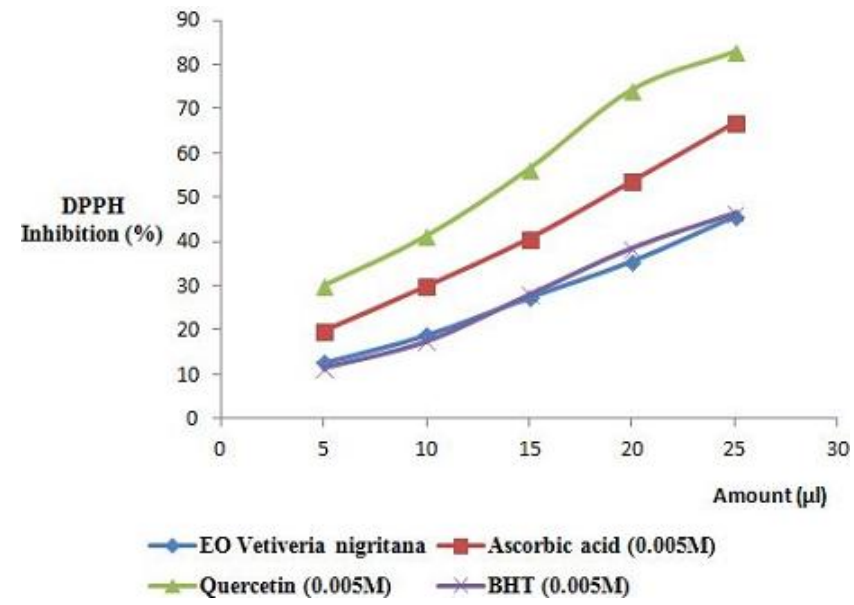

Fig. 2: DPPH radical scavenging power

The results obtained with the FRAP test are shown in figure 3 . The essential oil of $V$. nigritana roots showed a very lower reducing power comparing to ascorbic acid and quercetin. These results confirm those of the DPPH test. The antioxidant activity of the essential oil of $V$. nigritana roots is evaluated for the first time.

Antioxidant properties of essential oils such as lipid peroxidation, scavenging of free radicals, chelating metal ions, and 
reducing power are often come from their monoterpene hydrocarbons, oxygenated monoterpenes and sesquiterpenes [20, 21]. Some studies supported that phenolic components in the essential oil were the main source of antioxidant activity [22-24]. The essential oil of $V$. nigritana roots is poor in monoterpenes, oxygenated monoterpenes and phenolic components, which can explain its weak antioxidant activity. However Özkan and Erdoğan (2011) [25] showed that the essential of Origanum onites (Lamiaceae) had a free radical scavenging power greater than its two major phenolic component carvacrol and thymol.

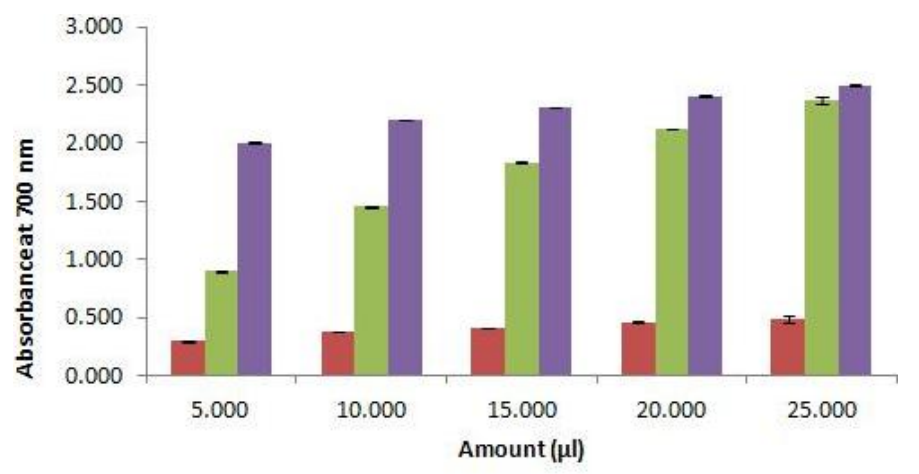

EO Vetiveria nigritana Ascorbic acid (0.1M) Euercetin (0.1M)

Fig. 3: Reducing power of the essential oil of Vetiveria nigritana roots.

\subsection{Antimicrobial activity}

The antimicrobial activity of the essential oil of Vetiveria nigritana roots has been evaluated by the disk diffusion method. The results presented in table 3 show that the essential oil of $V$. nigritana roots was active on all the microbial strains tested but at different levels.

The inhibition diameters (ID) of the essential oil were between $8.5 \mathrm{~mm}$ (Salmonella infantis, Salmonella typhimurium, Shigella flexnerii) and $23.5 \mathrm{~mm}$ (Bacillus subtilis). Applying the criteria of Carovic-Stanko et al. (2010) [13], the essential oil of $V$. nigritana roots had:

- Strong inhibitory action (ID $>15 \mathrm{~mm}$ ) on the strains of Bacillus, Clostridium perfringens, Escherichia coli ATCC 25922 and Staphylococcus hominis;

- Moderate inhibitory action (10 $\mathrm{mm} \leq \mathrm{ID} \leq 15 \mathrm{~mm})$ on the strains of Enterococcus faecalis, Escherichia coli $81 \mathrm{nr} .149$ SKN 541, Listeria monocytogenes, Micrococcus luteus, Salmonella enteridis, Salmonella nigeria, Shigella dysenteria, Staphylococcus aureus, Yersinia enterocolitica, Candida albicans, Candida kefir and Saccharomyces cerevisiae;

- Weak inhibitory action (ID $<10 \mathrm{~mm}$ ) on the strains of Pseudomonas aeruginosa, Salmonella infantis, Salmonella typhimurium, Shigella flexnerii and Candida tropicalis.

Table 3: Inhibition zone diameters $(\mathrm{mm})$ of the essential oil of Vetiveria nigritana roots $(15 \mu \mathrm{l})$ and standard antibiotics including the disc diameter $(6 \mathrm{~mm})$.

\begin{tabular}{|c|c|c|c|c|c|c|}
\hline \multicolumn{3}{|c|}{ Microbial strains } & \multicolumn{4}{|c|}{ Inhibition diameters (mm) } \\
\hline Bacterial strains & Gram & Origin & $\begin{array}{c}\text { EO } V . \\
\text { nigritana }\end{array}$ & $\begin{array}{c}\text { Tetracyclin } \\
(30 \mu \mathrm{g})\end{array}$ & $\begin{array}{c}\text { Ciprofloxaci } \\
\text { n }(5 \mu \mathrm{g})\end{array}$ & $\begin{array}{c}\text { Nystatin } \\
\text { (100UI) }\end{array}$ \\
\hline Bacillus cereus LMG13569 & Positive & Culture collection of London Metropolitan University & $19 \pm 1.41$ & $20 \pm 1.41$ & $27 \pm 1.41$ & - \\
\hline Bacillus subtilis ssp subtilis ATCC 6051 & Positive & ATCC & $23.5 \pm 0.71$ & $30.5 \pm 0.71$ & $34.5 \pm 0.71$ & - \\
\hline Clostridium perfringens & Positive & CRSBAN & $16 \pm 1.41$ & $27 \pm 1.41$ & $16.5 \pm 0.71$ & - \\
\hline Enterococcus faecalis ATCC 19433 & Positive & ATCC & $12 \pm 1.41$ & $24.5 \pm 0.71$ & $25 \pm 1.41$ & - \\
\hline Escherichia coli 81 nr.149 SKN 541 & Negative & Culture collection of Copenhagen University & $15 \pm 1.41$ & $16 \pm 1.41$ & $33 \pm 1.41$ & - \\
\hline Escherichia coli ATCC 25922 & Negative & ATCC & $17 \pm 1.41$ & $33.5 \pm 2.12$ & $22.5 \pm 0.71$ & - \\
\hline Listeria monocytogenes NCTC 9863 & Positive & Culture collection of London Metropolitan University & $14 \pm 1.41$ & $22 \pm 1.41$ & $31.5 \pm 0.71$ & - \\
\hline Micrococcus luteus SKN 624 & Positive & Culture collection of Copenhagen University & $12 \pm 0.00$ & $17 \pm 1.41$ & $32 \pm 1.41$ & - \\
\hline Pseudomonas aeruginosa ATCC 9027 & Negative & ATCC & $9.5 \pm 0.71$ & $12.5 \pm 0.71$ & $32.5 \pm 0.71$ & - \\
\hline Salmonella enteridis P167807 & Negative & Culture collection of London Metropolitan University & $10 \pm 0.00$ & $23 \pm 1.41$ & $31 \pm 1.41$ & - \\
\hline Salmonella infantis SKN 557 & Negative & Culture collection of Copenhagen University & $8.5 \pm 0.71$ & $21.5 \pm 2.12$ & $28 \pm 1.41$ & - \\
\hline Salmonella typhimurium SKN 1152 & Negative & Human & $8.5 \pm 0.71$ & $20 \pm 1.41$ & $26.5 \pm 0.71$ & - \\
\hline Salmonella nigeria SKN 1160 & Negative & Cocoa beans & $10 \pm 0.00$ & $18 \pm 1.41$ & $30.5 \pm 0.71$ & - \\
\hline Shigella dysenteria 370 & Negative & Culture collection of London Metropolitan University & $10 \pm 2.83$ & $23.5 \pm 2.12$ & $36.5 \pm 0.71$ & - \\
\hline Shigella flexneri USCC 2007 & Negative & Culture collection of London Metropolitan University & $8.5 \pm 0.71$ & $22.5 \pm 0.71$ & $31.5 \pm 0.71$ & - \\
\hline Staphylococcus aureus ATCC 2523 & Positive & ATCC & $12 \pm 0.00$ & $20.5 \pm 0.71$ & $24.5 \pm 0.71$ & - \\
\hline Staphylococcus aureus ATCC 25923 & Positive & ATCC & $15 \pm 0.00$ & $24 \pm 1.41$ & $27 \pm 1.41$ & - \\
\hline Staphylococcus aureus toxine $A+B$ & Positive & Culture collection of Copenhagen University & $15 \pm 1.41$ & $10.5 \pm 0.71$ & $06 \pm 00$ & - \\
\hline Staphylococcus hominis B246 & Positive & Maari (fermented baobab seeds) & $17 \pm 1.41$ & $30 \pm 1.41$ & $33.5 \pm 0.71$ & - \\
\hline Yersinia enterocolitica $8 A 30$ SKN 601 & Negative & Culture collection of Copenhagen University & $10 \pm 1.41$ & $15.5 \pm 0.71$ & $37.5 \pm 0.71$ & - \\
\hline Fungal strains & - & Origin & - & - & - & $\begin{array}{c}\text { Nystatin } \\
\text { (100UI) }\end{array}$ \\
\hline Candida albicans & - & Blood & $10 \pm 0.00$ & - & - & $22.5 \pm 0.5$ \\
\hline Candida kefir & - & Fura (fermented millet food) & $12.5 \pm 0.71$ & - & - & $24.5 \pm 0.5$ \\
\hline Candida tropicalis & - & Fura (fermented millet food) & $9 \pm 1.41$ & - & - & $20.5 \pm 0.5$ \\
\hline Saccharomyces cerevisiae KVL 013 & - & Culture collection of Copenhagen University & $11.5 \pm 0.71$ & - & - & $27.5 \pm 0.5$ \\
\hline
\end{tabular}

EO: Essential Oil.

ATCC: American Type Culture Collection.

CRSBAN: Centre de Recherche en Sciences Biologiques Alimentaires et Nutritionnelles. 


\subsection{MIC, MBC and MFC}

Minimum inhibitory concentrations (MICs), minimum bactericidal concentrations (CMBs) and minimum fungicidal concentrations (CMFs) of the essential oil of Vetiveria nigritana roots are shown in table 4 . MICs of the essential oil ranged from $1 \%$ to $8 \%(\mathrm{v} / \mathrm{v})$ for twelve bacterial strains and greater than $8 \%$ for the other tested strains. The lowest MIC is obtained with strains of Bacillus, C. perfringens, S. aureus ATCC 25923, S. aureus (toxin $\mathrm{A}+\mathrm{B}$ ) and $S$. hominis. The MBCs of essential oil of $V$. nigritana were $2 \%$ and $4 \%(\mathrm{v} / \mathrm{v})$ for ten bacterial strains and greater than $8 \%$ for the other bacterial strains. The essential oil had a bactericidal action $(1<\mathrm{MBC} / \mathrm{MIC} \leq 4)$ on the strains of Bacillus, $C$. perfringens, E. coli, L. monocytogenes, M. luteus, S. aureus ATCC 25923, S. aureus (toxin A + B) and S. hominis.

All the fungi strains tested were sensitive to the essential oil of $V$. nigritana with MIC value of $2 \%(\mathrm{v} / \mathrm{v})$ for Candida kefir and Saccharomyces cerevisiae, $4 \%$ for Candida albicans and $8 \%$ for Candida tropicalis. The MFCs of the essential oil were $4 \%$ for C. kefir and S. cerevisiae and greater than $8 \%$ for C. albicans and C. tropicalis. The essential oil had a fungicidal action $(1<\mathrm{MFC} /$ $\mathrm{MIC} \leq 4)$ on the strains of Candida kefir and Saccharomyces cerevisiae.

The essential oil of $V$. nigritana from Mali is active against Staphylococcus aureus, Enterococcus faecalis and Escherichia coli, less active against Pseudomonas aeruginosa and active against Candida albicans with MIC value of 1300 to 1400 $\mu \mathrm{g} / \mathrm{ml}[26]$. The results of the present study are in accordance with these results. However Adamua et al. (2005) [3] reported that Escherichia coli was resistant, Bacillus subtilis and Staphylococcus aureus were less susceptible and Pseudomonas aeruginosa was sensible to the essential oil of $V$. nigritana from Sudan. The variation of the antimicrobial activity of essential oils could be correlated to chemical composition variability [27, 28].

In recent years, several researchers have reported that monoterpenes or sesquiterpenes hydrocarbon and their oxygenated derivatives, which are the major components of essential oils, exhibit potential antimicrobial activity [27, 29, 30]. The relative good antimicrobial activity of the essential oil of $V$. nigritana roots can be attributed to the presence of sesquiterpene alcohols which represented about $23 \%$ of this essential oil. The essential oil of $V$. nigritana roots from Burkina Faso had a better action on Gram positive bacterial strains than Gram negative bacterial strains except for Escherichia coli strains. V. nigritana and V. zizanoïdes oils have a low activity against Gram-negative bacilli but are capable of inhibiting Gram-positive cocci growth with much higher efficiency [26]. The high concentrations of alcohols and ketones in these essential oils could explain their antibacterial activity. Essential oil of $V$. nigritana roots is rich in sesquiterpene components which have low antibacterial activity against Gram negative bacteria as described by some authors [31-33].

Table 4: Minimum inhibitory concentration (MIC), minimum bactericidal concentration (MBC) and minimal fungicidal concentration (MFC) of the essential oil of Vetiveria nigritana roots $0.03 \%$ to $8 \%(\mathrm{v} / \mathrm{v})$.

\begin{tabular}{|c|c|c|c|c|c|}
\hline \multicolumn{3}{|c|}{ Microbial strains } & \multicolumn{3}{|c|}{ EO $V$. nigritana $(\mathrm{v} / \mathrm{v})$} \\
\hline Bacterial strains & Gram & Origin & MIC & MBC & MBC/MIC \\
\hline Bacillus cereus LMG13569 & Positive & Culture collection of London Metropolitan University & $1 \%$ & $4 \%$ & 4 \\
\hline Bacillus subtilis ssp subtilis ATCC 6051 & Positive & ATCC & $1 \%$ & $4 \%$ & 4 \\
\hline Clostridium perfringens & Positive & CRSBAN & $1 \%$ & $4 \%$ & 4 \\
\hline Enterococcus faecalis ATCC 19433 & Positive & ATCC & $8 \%$ & $>8 \%$ & $>1$ \\
\hline Escherichia coli 81 nr.149 SKN 541 & Negative & Culture collection of Copenhagen University & $2 \%$ & $4 \%$ & 2 \\
\hline Escherichia coli ATCC 25922 & Negative & ATCC & $2 \%$ & $4 \%$ & 2 \\
\hline Listeria monocytogenes NCTC 9863 & Positive & Culture collection of London Metropolitan University & $2 \%$ & $4 \%$ & 2 \\
\hline Micrococcus luteus SKN 624 & Positive & Culture collection of Copenhagen University & $2 \%$ & $4 \%$ & 2 \\
\hline Pseudomonas aeruginosa ATCC 9027 & Negative & ATCC & $>8 \%$ & $>8 \%$ & $>1$ \\
\hline Salmonella enteridis P167807 & Negative & Culture collection of London Metropolitan University & $>8 \%$ & $>8 \%$ & $>1$ \\
\hline Salmonella infantis SKN 557 & Negative & Culture collection of Copenhagen University & $>8 \%$ & $>8 \%$ & $>1$ \\
\hline Salmonella typhimurium SKN 1152 & Negative & Human & $>8 \%$ & $>8 \%$ & $>1$ \\
\hline Salmonella nigeria SKN 1160 & Negative & Cocoa beans & $>8 \%$ & $>8 \%$ & $>1$ \\
\hline Shigella dysenteria 370 & Negative & Culture collection of London Metropolitan University & $>8 \%$ & $>8 \%$ & $>1$ \\
\hline Shigella flexneri USCC 2007 & Negative & Culture collection of London Metropolitan University & $>8 \%$ & $>8 \%$ & $>1$ \\
\hline Staphylococcus aureus ATCC 2523 & Positive & ATCC & $8 \%$ & $>8 \%$ & $>1$ \\
\hline Staphylococcus aureus ATCC 25923 & Positive & ATCC & $1 \%$ & $2 \%$ & 2 \\
\hline Staphylococcus aureus toxine $A+B$ & Positive & Culture collection of Copenhagen University & $1 \%$ & $4 \%$ & 4 \\
\hline Staphylococcus hominis B246 & Positive & Maari (fermented baobab seeds) & $1 \%$ & $4 \%$ & 4 \\
\hline Yersinia enterocolitica $8 A 30$ SKN 601 & Negative & Culture Collection of Copenhagen University & $>8 \%$ & $>8 \%$ & $>1$ \\
\hline Fungal strains & - & Origin & MIC & MFC & MFC/MIC \\
\hline Candida albicans & - & Blood & $4 \%$ & $>8 \%$ & $>2$ \\
\hline Candida kefir & - & Fura (fermented millet food) & $2 \%$ & $4 \%$ & 2 \\
\hline Candida tropicalis & - & Fura (fermented millet food) & $8 \%$ & $>8 \%$ & $>1$ \\
\hline Saccharomyces cerevisiae KVL 013 & - & Culture collection of Copenhagen University & $2 \%$ & $4 \%$ & 2 \\
\hline
\end{tabular}

EO: Essential oil.

ATCC: American Type Culture Collection.

CRSBAN: Centre de Recherche en Sciences Biologiques Alimentaires et Nutritionnelles. 


\section{CONCLUSION}

The essential oil of Vetiveria nigritana roots had an antioxidant activity but this activity is low compared to that of standard antioxidants such as quercetin and ascorbic acid.

The essential oil of $V$. nigritana also possessed good antimicrobial activity against most of the gram-positive bacterial strains tested. These results confirm the traditional usage of $V$. nigritana roots. The essential oil of $V$. nigritana roots could be used as potential natural antimicrobial agent.

Hence the use of essential oil of V. nigritana roots will be a cheaper and natural drug formulation to replace the commercially available chemical drug and also without any side effects.

\section{Financial support and sponsorship: Nil.}

Conflict of Interests: There are no conflicts of interest.

\section{REFERENCES}

1. Champagnat P, Bessière JM, Chezal JM, Chalchat JC, Carnat A P. New compounds from the essential oil of Vetiveria nigritana roots from Mali. Flavour and Fragrance Journal. 2007; 22:488-493.

2. Pousset JL. Plantes médicinales africaines, utilisation pratique. Paris: Agence de coopération culturelle et technique (ACCT); 1989.

3. Adamua HM, Abayeha OJ, Aghoa MO, Abdullahi AL, Ubac A, Dukkuc HU, Wufema BM. An ethnobotanical survey of Bauchi State herbal plants and their antimicrobial activity. Journal of Ethnopharmacology. 2005; 99:1-4.

4. Khalil MAL, Ayoub SMH. Analysis of the essential oil of Vetiveria nigritana (Benth.) Stapf root growing in Sudan. Journal of Medicinal Plants Research. 2011; 5 (32):7006-7010.

5. Kossouoh C, Moudachirou M, Adjakidje V, Chalchat JC, Figuérédo $\mathrm{G}$, Champagnat P. Chemical composition of essential oils of roots of Vetiveria nigritana (Benth.) Stapf from Benin. Journal of essential oil bearing plants. 2008; 11 (5):468-475.

6. Champagnat P, Figueredo G, Chalchat JC and Bessière JM. Essential oil composition of Vetiveria nigritana from Mali. Journal of Essential Oil Research. 2006; 18: 647-649.

7. Bassolé IHN, Nébié R, Savadogo A, Ouattara C T, Barro N, Traore A S. Composition and antimicrobial activities of the leaf and flower essential oils of Lippia chevalieri and Ocimum canum from Burkina Faso. African Journal of Biotechnology. 2005; 4 (10):11561160.

8. Adams RP. Identification of Essential oils Components by Gas Chromatography-Quadrupole Mass Spectrometry. Illinois, USA: Allured Publishing Corp., Card Stream, 2001.

9. Joulain D, König WA.The Altlas of Spectral Data of Sesquiterpene Hydrocarbons. Hamburg: E. B. Verlag, 1998.

10. Mc Lafferty FW, Stauffer DB. The Wiley NBS registry of Mass Spectral Data. 2nd ed. New York: J. Wiley and Son, 1989.

11. Van Den Dool H, Kratz PDJ. A generation of the retention index system inclg. linear temperature programmed gas-liquid partition chromatography. Chromatography. 1963; 11:463-471.

12. Joshi S, Prakash O, Pant AK, Mathela CS. Chemical Composition, and Antioxidant and Antimicrobial Activities of Alpinia nutans Rosc. Journal of Essential Oil Research. 2010; 22 (1):85-90.

13. Carovic-Stanko K, Orlic S, Politeo O, Strikic F, Kolak I, Milos M, Satovic Z. Composition and antibacterial activities of essential oils of seven Ocimum taxa. Food Chemistry. 2010; 119:196-201
14. Obame LC, Koudou J, Chalchat JC, Bassolé I, Edou P, Ouattara A S, Traoré A S. Volatile components, antioxidant and antibacterial activities of Dacryodes buettneri H. J. Lam. essential oil from Gabon. Scientific Research Essay. 2007; 2 (11):491-495.

15. Zouari N, Ayadi I, Fakhfakh N, Rebai A, Zouari S. Variation of chemical composition of essential oils in wild populations of Thymus algeriensis Boiss. et Reut., a North African endemic Species. Lipids in Health and Disease. 2012; 11(28).

16. Sousa EO, Colares AV, Rodrigues FFG, Campos AR, Lima SG and Costa JGM. Effect of collection time on essential oil composition of Lantana camara Linn (Verbenaceae) growing in Brazil Northeastern. Record of Natural Product. 2010; 4 (1):31-37.

17. Elhassan IA, Ayoub SMH. Effect of geographical location on essential oil content and composition of Xylopia aethiopica. American Journal of Research Communication. 2014; 2(1):251-261.

18. Anwar F, Hussain AI, Sherazi STH, Bhanger MI. Changes in composition and antioxidant and antimicrobial activities of essential oil of fennel (Foeniculum vulgare Mill.) fruit at different stages of maturity. Journal of Herbs, Spices and Medicinals Plants. 2009; 15:116.

19. Hussain AI, Anwar F, Sherazi STH, Przybylski R. Chemical composition, antioxidant and antimicrobial activities of basil (Ocimum basilicum) essential oils depends on seasonal variations. Food Chemistry. 2008; 108:986-995.

20. Loizzo MR, Tundis R, Conforti F, Menichini F, Bonesi M, Nadjafi F, Frega NG, Menichini F. Salvia leriifolia Benth (Lamiaceae) extract demonstrates in vitro antioxidant properties and cholinesterase inhibitory activity. Nutrition Research. 2010; 30:823830.

21. Tepe B, Daferera D, Sokmen A, Sokmen M, Polissiou M. Antimicrobial and antioxidant activities of essential oil and various extracts of Salvia tomentosa Miller (Lamiaceae). Food Chemistry. 2005; 90:333-340.

22. Kaya GI, Unver Somer UN, Konyalığlu S, Yalcin HT, Karabay Yavaşoğlu NU, Sarikaya B, Onur MA. Antioxidant and antibacterial activities of Ranunculus marginatus var. trachycarpus and R. sprunerianus. Turkish Journal of Biology. 2010; 34:139-146.

23. Dorman HJD, Surai P, Deans SG. In vitro antioxidant activity of a number of plant essential oils and phytoconstituents. Journal of Essential Oil Research. 2000; 12:241-248.

24. Ruberto G, Barata MT. Antioxidant activity of selected essential oil components in two lipid model systems. Food Chemistry. 2000; 69:167-174.

25. Özkan A, Erdoğan, A. A comparative evaluation of antioxidant and anticancer activity of essential oil from Origanum onites (Lamiaceae) and its two major phenolic components. Turk. J. Biol. 2011; 35:735742.

26. Champagnat P, Sidibé L, Forestier C, Carnat A, Chalchat J-C, Lamaison J-L. Antimicrobial Activity of Essential Oils from Vetiveria nigritana and Vetiveria zizanioides Roots. Journal of Essential Oil Bearing Plants. 2007; 10 (6):519-524.

27. Burt S. Essential oils: Their antibacterial properties and potential applications in food. International Journal of Food Microbiology. 2004; 94:223-253.

28. Lahlou M. Methods to Study the Phytochemistry and Bioactivity of Essential Oils. Phytotherapy Research. 2004; 18:435448.

29. Bajpai VK, Rahman R, Kang SC. Chemical composition and inhibitory parameters of essential oil and extracts of Nandina domestica Thunb to control food-borne pathogenic and spoilage bacteria. International Journal of Food Microbiology. 2008; 125:117122.

30. Cakir A, Kordali S, Zengin H, Izumi S, Hirata T. Composition and antifungal activity of essential oils isolated from Hypericum hyssopifolium and Hypericum heterophyllum. Flavour and Fragrance Journal. 2004; 19:62-68. 
31. Badawy MEI, Abdelgaleil SAM, Suganuma T, Fuji M. Antibacterial and Biochemical Activity of Pseudoguaianolide Sesquiterpenes Isolated from Ambrosia maritima against Plant Pathogenic Bacteria. Plant Protection Science. 2014; 50 (2):64-69.

32. Ozcelik B, Gurbuz I, Karaoglu T, Yeşilada E. Antiviral and antimicrobial activities of three sesquiterpene lactones from Centaurea solstitialis L. ssp. solstitialis. Microbiological Research. 2009;164: 545-552.

33. Rabe T, Staden J. Isolation of an antibacterial sesquiterpenoid from Warburgia salutaris. Journal of Ethnopharmacology. 2000;73: 171174.

\section{How to cite this article:}

Semde Z, Koudou J, Zongo C, Figueredo G, Somda MK, Ganou L, Traore AS. Chemical composition, antioxidant and antimicrobial activities of the essential oil of Vetiveria nigritana (Benth.) Stapf roots from Burkina Faso. J App Biol Biotech. 2017; 5 (04): 029-036. 